\title{
Replication analysis of the Coronavirus Anxiety Scale
}

\author{
Sherman A. Lee ${ }^{1 \oplus}$ \\ ${ }^{1}$ Christopher Newport University, Department of Psychology, Newport News, Virginia - USA
}

\begin{abstract}
As fear and anxiety rates increase during the COVID-19 crisis, the need to study and screen and treat vulnerable populations is vitally important. Accordingly, the Coronavirus Anxiety Scale, a mental health screener of coronaphobia, has been created to aid this effort. The results of a replication analysis reported here support the diagnostic and psychometric properties of this pandemic-related mental health screener. Considerations of this scale's use are also discussed.
\end{abstract}

Keywords: Anxiety, coronaphobia, coronavirus, CAS, COVID-19

\section{INTRODUCTION}

As the COVID-19 crisis continues to upend the global economy and everyday life, many people live with fear and anxiety. Frontline workers, like medical staff, are particularly vulnerable because they work in dangerous situations and are often isolated from their families and sources of support (1). Because this pandemic-related anxiety has been shown to correlate strongly with depression, generalized anxiety, and suicidal ideation (2), it is important that health professionals appropriately and efficiently screen and treat these at-risk individuals (3).

To aid in this process, I created a mental health screener of clinical anxiety (Corona Anxiety Scale [CAS]; see Table 1) related to the coronavirus crisis, otherwise known as "coronaphobia" (4), that has quickly gained international use among researchers and health professionals (5). Although this instrument demonstrated strong psychometric and diagnostic qualities in the original CAS investigation, these findings have not been verified on an independent sample. To ensure that the CAS truly embodies qualities worthy of a widely used mental health screener, replication analyses on this scale need to be conducted and the results should be peer-reviewed.

To address this essential concern, I examined unanalyzed data from a study recently published in the journal Psychological Medicine that focused on the mental health characteristics of people with coronaphobia (2). I chose this dataset because the sample size is sufficiently large $(\mathrm{n}=1237)$ and demographically similar to the U.S. population (72.6\% White; $54.6 \%$ male). This replication analysis consisted of a bootstrap (2000 samples) ML confirmatory factor analysis (CFA) on the items of the CAS and a receiver operating characteristic curve (ROC) analysis on the CAS total scores using the Work and Social Adjustment Scale as the criterion measure of functional impairment (6).

\section{METHOD}

\section{Participants and Procedure}

The study sample consisted of 675 men, 558 women, and 4 "other" with a combined mean age of 38.09 $(\mathrm{SD}=12.32)$ years. Most of the participants were White

How to cite this article: Lee SA. Replication analysis of the Coronavirus Anxiety Scale. Dusunen Adam The Journal of Psychiatry and Neurological Sciences 2020;33:203-205.

Correspondence: Sherman A. Lee, Christopher Newport University, Department of Psychology, Newport News, Virginia - USA 
Table 1: A copy of the Coronavirus Anxiety Scale

CAS

How often have you experienced the follow- Not at Rare, less than Several More than Nearly every day

\begin{tabular}{|c|c|c|c|c|c|c|}
\hline \multicolumn{2}{|c|}{ ing activities over the last 2 weeks? } & all & a day or two & days & 7 days & over the last 2 weeks \\
\hline 1. & $\begin{array}{l}\text { I felt dizzy, lightheaded, or faint, when } \\
\text { I read or listened to news about the } \\
\text { coronavirus. }\end{array}$ & 0 & 1 & 2 & 3 & 4 \\
\hline 2. & $\begin{array}{l}\text { I had trouble falling or staying asleep } \\
\text { because I was thinking about the } \\
\text { coronavirus. }\end{array}$ & 0 & 1 & 2 & 3 & 4 \\
\hline 3. & $\begin{array}{l}\text { I felt paralyzed or frozen when I } \\
\text { thought about or was exposed to } \\
\text { information about the coronavirus. }\end{array}$ & 0 & 1 & 2 & 3 & 4 \\
\hline 4. & $\begin{array}{l}\text { I lost interest in eating when I thought } \\
\text { about or was exposed to information } \\
\text { about the coronavirus. }\end{array}$ & 0 & 1 & 2 & 3 & 4 \\
\hline 5. & $\begin{array}{l}\text { I felt nauseous or had stomach } \\
\text { problems when I thought about or was } \\
\text { exposed to information about the } \\
\text { coronavirus. }\end{array}$ & 0 & 1 & 2 & 3 & 4 \\
\hline & Column totals & + & ${ }^{+}$ & + & ${ }^{+}+$ & ${ }^{+}$ \\
\hline
\end{tabular}

Note. The CAS was created by Sherman A. Lee, PhD., and originally published in the journal Death Studies. https://doi.org/10.1080/07481187.2020.1748481

$(\mathrm{n}=898 ; 71.9 \%)$, followed by Black $(\mathrm{n}=129 ; 10.4 \%)$, Asian $(\mathrm{n}=106 ; 9.6 \%)$, Hispanic $(\mathrm{n}=85 ; 6.9 \%)$, and "other" ( $\mathrm{n}=19 ; 1.5 \%)$. The majority of the participants had a Bachelor's degree or higher $(n=715 ; 57.8 \%)$ and had not been diagnosed with the coronavirus $(n=1117$; 95.1\%).

The research for this study was approved by the institutional review board of Christopher Newport University (USA). The participants were recruited on April 2, 2020, through Amazon MTurk in exchange for payment (US \$ 0.50) and were eligible if they provided consent and information that was valid and complete. Data were collected using Survey Monkey software and analyzed using IBM SPSS version 26 and IBM AMOS version 25 .

\section{Measures}

Work and Social Adjustment Scale (WSAS): The WSAS was used to measure functional impairment due to the coronavirus outbreak (6). Participants were asked to rate five items of the WSAS, using a 9-point severity scale ( $0=$ "not at all" to $8=$ "very severely"), regarding how much impairment they experienced because of the coronavirus outbreak. Based on a WSAS cut score of $\geq 21,35.0 \%$ of the sample was classified as functionally impaired. Cronbach's a was 0.78 .

Coronavirus Anxiety Scale (CAS): The CAS was used to measure coronaphobia (5). Participants were asked to rate five items of the CAS, using a 5-point frequency scale $(0=$ "not at all" to $4=$ "nearly every day over the last 2 weeks"), regarding how often they experienced physiologically-based symptoms of fear or anxiety when exposed to coronavirus-related thoughts or information. Based on a CAS cut score of $\geq 9,25.4 \%$ of the sample was classified as dysfunctionally anxious. Cronbach's a was 0.92 .

\section{RESULTS}

The results of the CFA demonstrated that the CAS is a highly reliable $(\alpha=0.92)$ and factorially valid measure $\left(\chi^{2}[5]=25.12, \mathrm{p}<0.001\right)$ that meets conventional standards for model fit (CFI=1.00; TLI $=0.99$; $S R M R=0.01$; RMSEA $=0.06$ [90\% CI 0.04, 0.08]) (7). The results of the ROC analysis also confirmed that the CAS has solid discrimination ability, as determined by a convex pattern on a ROC graph and an AUC value of $0.80(\mathrm{p}<0.001)$, as well as a strong specificity rate of $89 \%$. However, the CAS cut score $\geq 9$ yielded a sensitivity of $53 \%$ for this sample, which was well below the $90 \%$ value reported in the original CAS investigation. The CAS cut score had to be lowered to $\geq 5$ in order for the sensitivity rate to be acceptable at $71 \%$. Although this cut score reduced the specificity rate to $74 \%$, the diagnostic values were still within acceptable ranges for mental health screening.

\section{DISCUSSION}

Taken together, the results of this replication analysis support the CAS as a psychometrically sound mental health screener with acceptable classification features. 
The one aspect of the CAS that did not replicate was its ability to detect individuals who were functionally impaired by their coronavirus anxiety. The original cut score of $\geq 9$ appeared to be too stringent for this sample and had to be lowered to $\geq 5$ in order for the CAS to have a reasonable sensitivity rate. This discrepancy may reflect the differences in the samples. The original CAS investigation was exclusively composed of people with anxiety about the coronavirus, while the sample used in this analysis included people with and without anxiety because this particular study did not have an anxiety prerequisite. Although future research should clarify the source of this unexpected finding, current users of the CAS may consider lowering the cut score to $\geq 5$ when assessing the general population, but retaining the cut score of $\geq 9$ when screening at-risk or anxious groups.

Future research should also consider the appropriate adaptation of the CAS for populations outside of the U.S. On the Coronavirus Anxiety Project website (8), an online site for resources on coronaphobia, there are twenty translated versions of the CAS (as of June 30, 2020), including one in Turkish by Dr. Cuneyt Evren. Although these translated versions are important for the assessment and study of coronaphobia, it is crucial that psychometric studies be conducted before they are adopted for clinical and scholarly use. Specifically, these adapted versions of the CAS should meet rigorous standards of reliability and validity, as demonstrated by the Turkish version (9), and be culturally sensitive, as well (10).

\begin{tabular}{|c|c|c|}
\hline \multicolumn{2}{|c|}{ Contribution Categories } & \multirow{2}{*}{$\begin{array}{l}\text { Author Initials } \\
\text { S.A.L. }\end{array}$} \\
\hline \multirow{3}{*}{ Category 1} & Concept/Design & \\
\hline & Data acquisition & S.A.L. \\
\hline & Data analysis/Interpretation & S.A.L. \\
\hline \multirow{2}{*}{ Category 2} & Drafting manuscript & S.A.L. \\
\hline & Critical revision of manuscript & S.A.L. \\
\hline Category 3 & Final approval and accountability & S.A.L. \\
\hline \multirow{2}{*}{ Other } & Technical or material support & S.A.L. \\
\hline & Supervision & $\mathrm{N} / \mathrm{A}$ \\
\hline
\end{tabular}

Ethics Committee Approval: The research for this study was approved by the institutional review board of Christopher Newport University (USA).

Informed Consent: Written informed consent of all patients was obtained.

Peer-review: Externally peer-reviewed.

Conflict of Interest: None declared.

Financial Disclosure: No funding received for research.

\section{REFERENCES}

1. Lee SA. Coronavirus Anxiety Scale: A brief mental health screener for COVID-19 related anxiety. Death Stud 2020; 44:393401.

2. Wang Y, Zhao X, Feng Q, Liu L, Yao Y, Shi J. Psychological assistance during the coronavirus disease 2019 outbreak in China. J Health Psychol 2020; 25: 733-737.

3. Lee SA, Jobe MC, Mathis AA. Mental health characteristics associated with dysfunctional coronavirus anxiety. Psychol Med 2020:1-2. DOI: 10.1017/S003329172000121X. [Epub ahead of print].

4. Taylor S. The Psychology of Pandemics: Preparing for the Next Global Outbreak of Infectious Disease. Newcastle upon Tyne: Cambridge Scholars Publishing, 2019.

5. Asmundson GJG, Taylor S. Coronaphobia: Fear and the 2019nCoV outbreak. J Anxiety Disord. 2020; 70:102196.

6. Mundt JC, Marks IM, Shear MK, Greist JH. The Work and Social Adjustment Scale: a simple measure of impairment in functioning. Br J Psychiatry 2002; 180:461-4.

7. Brown TA. Confirmatory Factor Analysis for Applied Research. First ed., New York: Guilford Press, 2006.

8. Coronavirus Anxiety Project: The Coronavirus Anxiety Project. https://sites.google.com/cnu.edu/coronavirusanxietyproject/ home. Accessed May 3, 2020.

9. Evren C, Evren B, Dalbudak E, Topcu M, Kutlu N. Measuring anxiety related to COVID-19: A Turkish validation study of the Coronavirus Anxiety Scale. Death Stud 2020 DOI: 10.1080/07481187.2020.1774969 [Online ahead of print].

10. Geisinger KF. Cross-cultural normative assessment: translation and adaptation issues influencing the normative interpretation of assessment instruments. Psychol Assess 1994; 6:304-312. 